Студент, ekaterinafrolova17@mail.ru Факультет финансовых рынков, Финансовый университет при Правительстве РФ, Москва, Российская Федерация Научный руководитель:

Е. И. Куликова

Кандидат экономических наук, доцент Департамент финансовых рынков и банков, Финансовый университет при Правительстве РФ, Москва, Российская Федерация

\title{
Перспективы развития Private banking в российских коммерческих банках
}

Аннотация: В статье рассмотрены актуальные вопросы применения в сфере банковских услуг такого вида услуг, как Private banking. В перечне системно значимых кредитных организаций, утвержденных Банком России, на их долю которых приходится более $60 \%$ совокупных активов российского банковского сектора, количество их на текущий момент всего 11 банков. Именно эти банки предлагают услуги Private banking, перечень и перспективы развития которых рассмотрены в статье.

Ключевые слова: сфера банковских услуг, частное банковское обслуживание, Private banking, российские банки, системно значимые кредитных организаций.

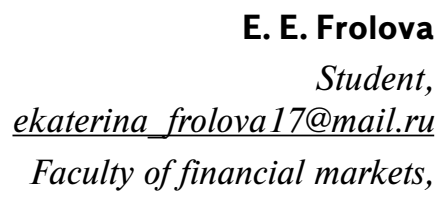

Financial University under the Government of the Russian Federation, Moscow, Russian Federation

Scientific Superviser:

E. I. Kulikova

Cand. Sci. (Econ.), Assoc. Prof.

Department of financial markets and banks,

Financial University under the Government of the Russian Federation,

Moscow, Russian Federation 


\section{Prospects for the development of Private banking in Russian commercial banks}

Annotation: The article deals with topical issues of application in the sphere of banking services of such type of services as Private banking. In the list of systemically significant credit institutions approved by the Bank of Russia, which account for more than $60 \%$ of the total assets of the Russian banking sector, their number at the moment is only 11 banks. These banks offer Private banking services, the list and prospects of which are discussed in the article.

Keywords: banking services, private banking, Private banking, Russian banks, systemically significant credit institutions.

С момента назначения Банка России мегарегулятором российского финансового рынка он вносит существенные изменения в политику банковского сектора экономики, тем самым, оптимизируя банковскую систему с целью очищения ее от нежелательных участников на рынке банковских услуг, а также от более слабых банков. Это связано с тем, что такие кредитные организации на рынке могут нанести существенный вред не только вкладчикам, но и клиентам, инвесторам, экономике в целом. Исходом данной ситуации явилось следующее: с 2014 по 2016 годы практически порядка у 400 банков были отозваны лицензии [1]. «Начиная с 2016-2017 гг. ситуация изменилась, что связано, на наш взгляд, с разочарованием инвесторов в данном виде инвестиций из-за снижения ставки по депозитам, санации в банковской сфере со стороны органов государственного управления, уменьшения количества филиалов и отделений и др. [6]».

Анализ нынешней экономической ситуации в стране позволяет предположить, что, скорее всего, данная тенденция сохранится в ближайшие несколько лет. Данный факт волнует собственников бизнеса, по причине того, что согласно п. 2 ст. 861 ГК РФ, являясь юридическими лицами, они обязаны проводить расчеты безналичным путем со своими контрагентами. Самое интересное в данном вопросе то, что средства юридических лиц никак не застрахованы, чего нельзя сказать о средствах физических лиц. Государство страхует их на сумму до 1,4 млн. рублей. Именно поэтому отзыв лицензий у кредитных организаций Баком России в первую очередь несет убытки именно юридическим лицам.

По этой причине вероятность отзыва лицензии банка - это риск для собственников бизнеса, которые являются их непосредственными 
клиентами. Эти клиенты, занимающиеся частным бизнесом, как правило, являются достаточно состоятельными. Как правило, у такой категории населения достаточно высокий спрос на банковские услуги, а именно, услуги Private banking.

Банк России утвердил перечень системно значимых кредитных организаций, на долю которых приходится более $61 \%$ совокупных активов российского банковского сектора (Указание Банка России от 22.07.2015 № 3737-У).

На данный момент времени количество этих банков утверждено Центральным Банком Российской Федерации, всего их 11. И стоит отметить, что именно на эти банки приходятся услуги Private banking, и в первую очередь, именно к этим банкам обращаются клиенты частного бизнеса, по причине высокого доверия населения этим кредитным организациям (см. табл. 1)

Таблица 1

Перечень системно значимых кредитных организаций [8]

\begin{tabular}{|c|l|c|}
\hline $\begin{array}{c}\text { № } \\
\text { П/п }\end{array}$ & \multicolumn{1}{|c|}{ Наименование кредитной организации } & Рег. № \\
\hline 1 & АО ЮниКредит Банк & 1 \\
\hline 2 & Банк ГПБ (АО) & 354 \\
\hline 3 & Банк ВТБ (ПАО) & 1000 \\
\hline 4 & АО «АЛЬФА-БАНК» & 1326 \\
\hline 5 & ПАО Сбербанк & 1481 \\
\hline 6 & ПАО «МОСКОВСКИЙ КРЕДИТНЫЙ БАНК» & 1978 \\
\hline 7 & ПАО Банк «ФК Открытие» & 2209 \\
\hline 8 & ПАО РОСБАНК & 2272 \\
\hline 9 & ПАО «Промсвязьбанк» & 3251 \\
\hline 10 & АО «Райффайзенбанк» & 3292 \\
\hline 11 & АО «Россельхозбанк» & 3349 \\
\hline
\end{tabular}

Такого рода клиенты, являющиеся владельцами наиболее крупного частного капитала, весьма значимы для банков, потому что могут стать главным источником устойчивых, долгосрочных пассивов.

Банковская система РФ на протяжении нескольких десятков лет вводит для более состоятельных клиентов индивидуальное банковское обслуживание. Индивидуальное банковское обслуживание в Российской Федерации имеет ряд особенностей, существенно отличающихся 
от услуг Private Banking за рубежом, а также и из-за своего более позднего становления именно как отдельной услуги.

Private Banking - это частное банковское обслуживание, которое предоставляется для состоятельных клиентов. Также Private Banking это доступ к лучшим технологиям финансового рынка, это право иметь личного менеджера и получать консультации по возникающим финансовым вопросам [2].

Важнейший этап развития сегмента Private banking в банках РФ пришелся на 1997-2000 годы. Этот процесс был связан с формированием личных капиталов, а также с необходимостью передачи денежных средств в управление профессионалам. Кризис 1990-х годов указал на необходимость следовать проверенным годами принципам управления частным капиталом.

Private banking представляет собой в первую очередь частное обслуживание банком состоятельных лиц. При этом подход банка при обслуживании такой категории клиентов существенно отличается от стандартного банковского обслуживания физических лиц. В этом случае банк для клиента выступает в качестве личного финансиста, решающего многочисленные вопросы. Поэтому часто применяется такой термин - «личный банкир».

Очевидно, немаловажны такие составляющие, как особенные условия обслуживания, например выезд топ-менеджера к клиенту для заключения сделки в удобное место и время, предоставление небанковских услуг (например, бронирование гостиницы, покупка билетов, также организация эксклюзивных туров и т.д.). Еще следует отметить, что большую роль в Private Banking играет не только оперативность, но и возможность особого графика обслуживания (24 часа в сутки). Хотя большинство клиентов сферы Private Banking приходят в банк для решения финансовых вопросов и редко просят о какой-либо еще услуге. Менеджеры банков сами предлагают помощь в различных сферах, которые не связаны напрямую с банковским обслуживанием [9].

Для многих стран понятие Private Banking не является новым, тем не менее в России рынок Private Banking начал свою историю относительно недавно, чуть более 20 лет назад. На данный момент Private Banking в России находится в процессе формирования.

Характерными особенностями рынка Private Banking в нашей стране является то, что он в основном обслуживает только местных клиентов, 
ориентируя свое внимание в большей степени на мегаполисы, такие как Москва и Питер. Это объясняется сосредоточением обеспеченных лиц в этих городах. Однако прослеживается экспансия сегмента Private Banking и в регионы, а это приводит к увеличению региональных банков, которые являются участниками рынка частного банкинга. Несомненно, большинство хайнетов концентрируются по-прежнему в Москве, Санкт-Петербурге, но группа состоятельных клиентов уже успела сформироваться и в других крупных российских городах, например: Екатеринбург, Казань, Нижний Новгород, Сургут, Самара Тюмень, Уфа и др.

Рынок Private Banking России не достигает уровня среднемирового значения. Однако 6,7\% миллиардеров мира по итогам 2017 года являются гражданами Российской Федерации. Получается, что в РФ более обеспеченных лиц меньше, чем в среднем в мире [4]. 0,1\% населения страны составляют лица, капитал которых превышает метку 1 млн. долл. США.

Следующей чертой частного банкинга в России является то, что потребитель рынка услуг Private Banking был продолжительное время моложе типичного привилегированного клиента в силу того, что обычно это был человек, создавший своё состояние в 1990-е годы, т. е. российский РВ в своем большинстве имеет дело с капиталом первого поколения.

Следовательно, долгое время целью российского клиента было именно приумножение капитала, и, как следствие, он выбирал для себя наилучшие стратегии роста. Услуги в области наследования капитала особой популярностью не пользовались.

По сути, специфика Private Banking не только во всём мире, но и в России состоит в том, что каждая банковская услуга должна быть разработана и сформирована индивидуально под потребности определенного клиента.

С 2013 по 2018 гг. общий объем вкладов физических лиц увеличился на 60\%. Что подтверждает также необходимость и возможность развития Private Banking в России.

Объем крупных вкладов, размер которых превышает 5 млн. руб. за 2017 год увеличился на 30\% - с 5,5 до 7,4 трлн. руб.

Отмечу, что $32 \%$ всех вкладов приходится на состоятельных клиентов. В последнее годы наметился рост спроса на индивидуальное банковское обслуживание. Согласно мнению банковских экспертов, подобный тренд сохранится, а коммерческие банки продолжат расширять- 
ся в сегменте Private Banking и будут модифицировать свои продуктовые линейки.

В России, по данным за 2018 год, проживает значительное количество собственников крупного частного капитала.

Наша страна находится на 5 месте в мире по количеству миллиардеров, об этом свидетельствуют данные таблицы 2.

Таблица 2

Количество миллионеров по странам в 2018 г. [10]

\begin{tabular}{|l|c|}
\hline \multicolumn{1}{|c|}{ Страна } & Количество, чел. \\
\hline США & 540 \\
\hline КНР & 251 \\
\hline Германия & 120 \\
\hline Индия & 84 \\
\hline Россия & 77 \\
\hline Гонконг & 64 \\
\hline Великобритания & 50 \\
\hline Италия & 43 \\
\hline
\end{tabular}

Сегодня состоятельные лица предпочитают видеть банк не только как продавца банковских продуктов, но также как опытного советника в сфере финансов. Одна из важнейших перспектив развития Private Banking обслуживания в РФ - это поддержание конкурентоспособности за рубежом, выход на мировые рынки услуг элитного обслуживания.

Следовательно, можно сказать следующее: рынок частного банковского обслуживания в России находится на стадии формирования и развития. Индустрия сегмента Private Banking расширяется, тем самым привлекая новых состоятельных лиц.

К особенностям российского Private Banking по сравнению с зарубежными банками можно отнести следующие:

- слабое внимание к совершенствованию программам лояльности, направленных на увеличение разнообразия банковских продуктов, для привлечения клиентов с различными требованиями;

- ограниченный перечень услуг, предоставляемых банками; 
- менее жесткие требования банков к частным клиентам, а также более низкие комиссионные, что связано с их невысоким доверием к банковской системе России.

Так, например, в зарубежных банках размер комиссии является заградительным для отсечения нецелевого сегмента, а в России комиссии вполне доступны и могут варьироваться в пределах от 4 тысяч до 150 тысяч рублей в год (а в более крупных банках - от 100 тысяч до 150 тысяч рублей).

В последние годы Центральный Банк оптимизирует структуру банковского сектора России, на что указывает активный отзыв лицензий банков. Таким образом происходит перераспределение некоторой части средств сегмента Private Banking в пользу крупных коммерческих банков, поскольку общий объем вкладов физических лиц в банках с отозванной лицензией кратно превышает объем средств, аккумулированный Ассоциацией страхования вкладов (АСВ). В этой связи надежность банка становится одним из главных факторов для вкладчика.

По результатам исследования обслуживания частного банковского капитала, основную часть клиентов Private Banking в России составляют наемные руководители и владельцы бизнеса, а также топ-менеджеры, что позволяет выделить следующие сегменты Private Banking:

1) состоятельные люди, главной целью которых является накопление и приумножение собственного капитала. Как правило, это владельцы среднего бизнеса или менеджеры высшего звена, предпочитающие VIP-сервис;

2) обеспеченные клиенты, требующие более сложных подходов к управлению капиталом, что выражается в разработке персональной стратегии управления портфелем и инвестирования, основанной на диверсификации инвестиционного портфеля.

Клиентами банковского сегмента Private Banking являются собственники бизнеса - 48\%; топ-менеджеры - 25\%, государственные служащие $-11 \%$, представители других сфер деятельности - 16\% [5].

Состоятельные клиенты Private Banking чаще всего отдают предпочтения депозитам для хранения своих денежных средств, и в большинстве случаев в рублях, хотя доля валютных сбережений у привилегированных слоев населения выше по сравнению с вкладчиками массового сегмента. На вклады в инвестиционные инструменты идут всего $10 \%$ средств, такие как: еврооблигации, доверительное управление, структурные продукты и другие. 
Сейчас на российском рынке выделяют несколько основных участников сферы Private Banking. В первую очередь, это такие крупные коммерческие банки, как Сбербанк, Газпромбанк, ВТБ, Альфа-Банк, ЮниКредит, Росбанк и другие. Доля средств VIP-клиентов в пассивах крупных российских банков составляет от $20 \%$ до $60 \%$ в совокупном объеме средств физических лиц [5].

Frank Research Group определила лучшие банки в сегменте Private Banking на Российском рынке в 2018 году. Sberbank Private Banking был признан лучшим банком, обслуживающим VIP клиентов. В Топ-5 банков частного обслуживания также вошли Citigold Private Client Friedrich Wilhelm Raiffeisen, Открытие PrivateBanking и Private Banking ЮниКредит Банка.

Итак, уникальность Private Banking заключается в клиентоориентированности: есть чёткая сегментация клиента в рамках частного обслуживания, цель которого является выявление индивидуальных потребностей клиентов, для индивидуальной работы с владельцем частного большого капитала определяется свой персональный менеджер.

Кроме классических банковских к важнейшим услугам, оказываемым Private Banking, относят: доверительное управление денежными средствами, финансовое планирование, услуги консультационного характера, услуги по поводу наследования капитала, услуги инвестиционного характера.

Число обеспеченных лиц в мире с годами неуклонно растет, соответственно потенциал рынка Private Banking не стоит на месте.

Отечественный рынок личного банкинга сравнительно молодой. Банковские институты нашей страны не имеют должного опыта в сегменте частного обслуживания и по многим параметрам уступают иностранным конкурентам:

- в уровне качества предлагаемых продуктов и услуг;

- в недостаточно высокой квалификации персонала;

- в сравнительно небольшом перечне услуг, предоставляемых клиентам.

Российской Федерации присуще концентрация хайнетов, а, следовательно, и рынка частного банкинга в таких городах, как Москва и Санкт-Петербург. Все же заметна тенденция к экспансии рынка Private Banking в регионы. При этом на фоне политики укрупнения банков основными участниками российского рынка Private Banking, которая 
проводится со стороны Банка России, становятся более крупные банки с государственным участием.

Таким образом, рынок Private Banking - это привлекательный для банков рынок, но, к сожалению, он недостаточно развит в России. Российским банковским институтам еще предстоит набираться опыта работы в данном сегменте и постоянно стараться повышать качество предоставляемых услуг.

\section{Список литературы}

1. Банковское дело. Организация деятельности коммерческого банка: учебник / Г.Н. Белоглазова, Л.П. Кроливецкая. - М.: Издательство Юрайт; ИД Юрайт, 2011. 422 с.

2. Гусев А.И. Современные тенденции отечественного Private Banking // Банковское дело. 2012. № 3. С. 58-59.

3. Деятельность кредитно-финансовых институтов [Текст]: учебник / под ред. Б.Б. Рубцова. - М.: Кнорус, 2019. 232 с.

4. Дудко В. В. Организационные элементы обслуживания VIP-клиентов коммерческого банка // Вестник Северо-Кавказского государственного технического университета. 2010. № 1 (22). С. 125-129.

5. Козлова Е.C. Private Banking в российских коммерческих банках // Сборник материалов III Международной научной конференции студентов специалитета, бакалавриата и магистратуры. - Воронеж: «Научная книга», 2019. С. 99-101.

6. Куликова Е.И. Расширение спектра инвестиционных инструментов для частного инвестора на российском финансовом рынке // Финансовая жизнь. 2018. № 2. С. 67-71.

7. Основные направления единой государственной денежно-кредитной политики на 2017 год и период 2018 и 2019 годов (одобрено Советом директоров Банка России 10.11.2017).

8. Официальный сайт Банка России. [Электронный ресурс] Режим доступа: http: // www.cbr.ru.

9. Private Banking - как направление деятельности. URL: http://lovecredit.ru/st/private-banking-kak-napravlenie-deyatelnosti.

10. Forbes. Мировой рейтинг миллиардеров - 2018. [Электронный ресурс] URL: http: // www.forbes.ru. 


\section{References}

1. Banking. The organization of activity of commercial Bank: a textbook / G. N. Beloglazova, L. P. Krolewiecka. - M.: yurayt publishing House; yurayt publishing house, 2011. $422 \mathrm{c}$.

2. Gusev, A. I. Modern trends of domestic Private Appd // Banking. 2012. No. 3. Pp. 58-59.

3. Activities of financial institutions [Text]: the textbook / under the editorship of B. B. Rubtsov. Moscow: KnoRus, 2019. 232 p.

4. Dudko V. V. Organizational elements of the VIP-clients servicing commercial Bank // Vestnik of the North-Caucasian state technical University. 2010. No. 1 (22). Pp. 125-129.

5. Kozlova E. S. Private Banking in Russian commercial banks // Proceedings of the III International scientific conference of students of specialty, bachelor and master. - Voronezh: «Scientific book». 2019. Pp. 99-101.

6. Kulikova E. I. Expanding the range of investment instruments for private investors in the Russian financial market // Financial life. 2018. No. 2. Pp. $67-71$.

7. The main directions of the unified state monetary policy for 2017 and the period of 2018 and 2019 (approved by the Board of Directors of the Bank of Russia 10.11.2017).

8. Official website of the Bank of Russia. [Electronic resource] access Mode: http: // www.cbr.ru.

9. Private Banking-as a direction of activity. URL: http://love-credit.ru/st/ private-banking-kak-napravlenie-deyatelnostiю.

10. Forbes. World ranking of billionaires-2018. [Electronic resource] URL: http: // www.forbes.ru. 